\title{
Bio-tecnologías ambientales para el tratamiento de residuos ganaderos
}

\author{
Environmental biotechnologies for \\ livestock manure treatment
}

\author{
Cristina Elizabeth Vélez-Sánchez-Verín ${ }_{2}^{1}$ Carmelo Pinedo-Álvarez, Oscar A. Viramontes- \\ Olivas $^{1}$, Carlos Ortega Ochoa Alicia Melgoza-Castillo ${ }^{1}$.
}

\begin{abstract}
Resumen
La gestión para el manejo y tratamiento de residuos producidos en sociedades modernas representa un reto para la atenuación de la contaminación ambiental. Los residuos de tipo orgánico requieren de tecnologías que ayuden a minimizar el impacto ambiental, principalmente en áreas donde los excedentes dificultan su absorción en el suelo de manera natural. Algunas tecnologías utilizadas en el tratamiento de desechos ganaderos representan alternativas eficaces para reducir impactos ambientales, pérdida de nutrientes así como para generar productos de valor comercial. Sin embargo, la selección y adaptación de estas técnicas suelen dificultarse de acuerdo a diversas estrategias de manejo y legislaciones que existen entre países y regiones. Adicionalmente, es importante que los productores consideren los aspectos sociales, ecológicos y económicos para adoptar técnicas de fácil operatividad, sin costos excesivos, que satisfagan sus requerimientos y puedan realizarse bajo el marco de legislación ambiental vigente. Entre las tecnologías que generalmente se han adoptado en diversas regiones y comunidades rurales sobresalen la bio-metanización y el compostaje. Este documento explora aquellas técnicas que han sido desarrolladas para el tratamiento de estiércoles asociados a los procesos de eliminación, concentración, conversión o en la inmovilización de uno o más de los componentes presentes en los mismos.
\end{abstract}

Palabras clave. Deterioro ambiental, tecnologías y desechos pecuarios

\begin{abstract}
Solid waste management is a challenge for modern societies in order to reduce environmental pollution. Among sort of wastes the organic requires technology that minimizes the environmental impact mainly in such places where the amount of waste makes difficult its natural disposal. Several technologies, already in use represent good alternatives to manage livestock waste and reduce environmental impact. However, there are difficult to select and adopt technology that fits management strategies and environmental laws between countries and within regions. In addition, livestock producers may consider social, ecological, an economic factors in order to adopt low cost and easy operation technology. That technology should fit producer's expectations and legal environmental requirements. Among other techniques, the bio-metanization and compost have been widely used at regional and community level. This document discusses some techniques developed to manage cattle manure regarding reduction, concentration, conversion, and immobilization of one or several components contained on it. These results will provide options that fit producer requirements and allow them to choose strategies that reduce and control pollution and obtain low cost by-products.
\end{abstract}

Key words: Environmental degradation, technologies, livestock waste

\footnotetext{
${ }^{1}$ Profesores de la Facultad de Zootecnia de la Universidad Autónoma de Chihuahua. Periférico Francisco R. Almada, Km. 1. Chihuahua, Chihuahua, México. Código Postal 31031. México Tel. (614) 434-0303. cvelez@uach.mx.
} 


\section{Introducción}

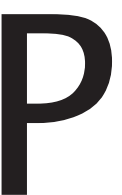

ara poder llevar a cabo la gestión adecuada de residuos que se generan, se han desarrollado diversas biotecnologías para el tratamiento de desechos sólidos y líquidos. En este contexto, diversos países han establecido programas de manejo y tecnologías de revalorización con el fin de disminuir el deterioro ambiental causado por acumulaciones, buscando que no implique costos excesivos, bajo un marco de estricta y transparente legislación ambiental (Burton y Turner, 2003).

Para el sector ganadero los residuos orgánicos representan una fuente de nutrientes para el mejoramiento de cultivos y generación de combustibles y fertilizantes; sin embargo, por su alto contenido de metales pesados, también contribuyen a generar impactos negativos en suelo y agua (Petersen et al., 2007). Esto se agudiza en las unidades de producción intensivas con altas emisiones de olores y contaminantes y el riesgo de esparcimiento de enfermedades entre el ganado (Miller y Berry, 2005).

La aplicación de estrategias de tratamiento que permitan reciclar nutrientes provenientes de desechos ganaderos representan una alternativa eficaz para reducir problemas de contaminación; sin embargo, deben considerarse características y condiciones ecológicas, socioculturales y económicas de cada ecosistema agrícola (Olymar y Reyes, 2003). Los mecanismos por los cuales estos sistemas operan pueden ser: a) la estabilización del material orgánico con una relación óptima carbono - nitrógeno $(\mathrm{C} / \mathrm{N})$ y la factibilidad de aplicarse a cultivos en el tiempo propicio, b) concentración y transporte en áreas deficientes de nutrientes, c) eliminación de compuestos indeseables tales como emisiones de $\mathrm{NH}_{3} \mathrm{O} \mathrm{CH}_{4}, \mathrm{O}$ d) valorización del residuo (Petersen et al., 2007).

Este trabajo examina técnicas que han sido desarrolladas para el tratamiento de estiércoles asociados a los procesos de eliminación, concentración, conversión o inmovilización de uno o más componentes presentes en los mismos; con el propósito de proporcionar al productor opciones que les permitan seleccionar las estrategias más adecuadas en la reducción y control de la contaminación y/o en la obtención de productos a costo mínimo.

\section{Estrategias de tratamiento.}

Existe una variedad de sistemas de tratamiento para el manejo de residuos sólidos y líquidos, cada uno de ellos se caracterizan por un método particular de eliminación, concentración, conversión o inmovilización de uno o más de los componentes presentes en el estiércol (Bohm, 2004). Aun cuando no logran por sí mismos alcanzar una completa reducción en la contaminación, los productores tienen varias opciones que analizadas y combinadas de manera apropiada, podrían conducir a una estrategia de reducción y control de la contaminación a costos mínimos o a la fabricación de productos potencialmente vendibles (Grommen y Verstraete, 2002).

\section{Estiércoles sólidos.}

Entre las tecnologías utilizadas para el tratamiento de estiércoles frescos y sólidos las más utilizadas son: 
Esparcimiento de estiércol. Aunque la distribución del estiércol fresco a las plantas no es un proceso de tratamiento, representa la alternativa más común y extendida en explotaciones de pequeña escala en países en desarrollo que carecen de recursos económicos y socio culturales para la aplicación de tecnologías y estrictas regulaciones ambientales (Riethmuller, 2003). En el estado de Chihuahua, esta práctica se manifiesta de manera general en sectores ganaderos del medio rural (Vélez et al., 2005) donde los sistemas de producción intensiva se han incrementado como un medio de apoyo a la economía familiar. Los problemas derivados de esta práctica se atribuyen al alto contenido de nitrógeno (orgánico y amoniacal) y de material orgánico que para los microorganismos del suelo que requieren una proporción determinada de $\mathrm{C} / \mathrm{N}$ resulta excesiva, lo que origina una elevada demanda de oxígeno (Ocyasa Medioambiental S.L., 2002). Ello provoca una bio-disponibilidad limitada de nitrógeno por las plantas que es consumido por los microorganismos, una disminución del pH de suelo causada por la alta demanda de oxígeno y acidificación que empobrece y dificulta el desarrollo vegetal (Tamminga, 2003). En regiones con producción excesiva de estiércoles que rebasan los límites legales establecidos para su aplicación a cultivos se recomienda transportarlo a otras áreas, aplicar un tratamiento, ajustar la densidad del ganado o balancear los niveles de nutrientes en las dietas del animal (Sims et al., 2005). Cualquiera de estas opciones involucran aspectos sociales y costos para su operación (Verstraete, 2002).

Almacenamiento. El almacenamiento de estiércoles en fosas por períodos adecuados favorece la eliminación de organismos patógenos presentes en las excretas y permite esperar a que las condiciones de aplicación sean adecuadas para que las plantas asimilen con mayor eficacia los nutrientes y reducir la posibilidad de contaminación al medio (Petersen et al., 2003). Las instalaciones de manejo y almacenamiento pueden ser diseñadas para permitir aliviar muchos de los problemas ambientales descritos en suelos y agua; sin embargo cuando la contaminación deriva de una excesiva cantidad de nutrientes en el lugar, esta medida suele ser insuficiente y debe combinarse con otras técnicas de tratamiento como separación, procesos biológicos, desnitrificación o transporte a zonas periféricas (Ocyasa Medioambiental S.L., 2002). Aunque el almacenamiento no evita la emisión total de gases invernadero y no permite la utilización bioenergética de la biomasa (Amon et al., 2006) es posible reciclar nutrientes con riesgos higiénicos controlados y contenidos de metales pesados que no excedan de los límites autorizados en el suelo (Nicholson y Chambers, 2006).

Separación de fases. La separación de la fase líquida y sólida del estiércol facilita el manejo de desechos y reduce problemas de almacenamiento y transporte. De este modo, las fracciones sólidas y liquidas pueden ser utilizadas de forma aislada de manera que el productor les confiera un valor agregado. Por su bajo contenido de humedad la fracción sólida puede ser fácilmente composteada generando un producto estable de fácil transportación o una vez seca, se puede amontonar y manipular sin olores ofensivos (Sorensen y Thomsen, 2005); la fracción líquida por su 
alto valor fertilizante, puede ser bombeada a terrenos distantes sin riesgos de taponamiento en tuberías o bien, puede ser tratada en lagunas de fermentación aeróbicas o anaeróbica. En sistemas biológicos el volumen del material orgánico que se fermenta depende del contenido de sólidos volátiles (SV), demanda biológica de oxígeno (DBO) y población bacterial; la separación de sólidos presentes en el estiércol fresco trae como resultado una reducción de la carga diaria de SV que ingresan en lagunas y por consecuencia del volumen a tratar (30 a 50 $\%)$ lo que incrementa la eficiencia del proceso. Igualmente se disminuyen los volúmenes de almacenaje desde 6 a $10 \%$ de la mezcla ((Burak et al., 2005), lo que se refleja en menores costos de construcción, mantenimiento y facilidad en el manejo de residuos. Una desventaja de esta técnica podría ser la poca rentabilidad en operaciones ganaderas de pequeña escala ante la necesidad de contar con equipo de bombeo y filtros para el manejo de desecho sólidos y líquidos (Campos, 2001a).

Tratamientos biológicos. Las aguas residuales y excretas de ganado pueden ser estabilizados mediante tratamientos biológicos aerobios o anaerobios que en este último caso, la concentración de oxígeno es perjudicial. Estos procesos permiten el aprovechamiento del potencial energético de la biomasa, disminuyen su carga contaminante y generan subproductos estabilizados con valor fertilizante y energético (Soyez y Plickert, 2002); los criterios para su selección son la carga orgánica, las condiciones económicas y ambientales existentes, así como las ventajas y desventajas que cada proceso ofrece. Para residuos con una demanda biológica de oxigeno $\left(\mathrm{DBO}_{5}\right)$ menor de $4000 \mathrm{mg}^{-1} \mathrm{se}$ recomiendan los tratamientos aerobios y los anaeróbicos para aquellos con $\mathrm{DBO}_{5}$ mayor o igual a $4000 \mathrm{mg}^{-1}$ (Sosa et al., 2003). Los tratamientos aerobios son más rápidos y efectivos para la remoción del material orgánico oxidable, la cual esta en función del contenido de oxigeno $\left(\mathrm{DBO}_{5}\right)$ y puede ser alcanzable en $5 \mathrm{~d}$. Aunque en los procesos anaeróbicos este tiempo es frecuentemente mayor a $20 \mathrm{~d}$ (Petersen et al., 2007), representan una forma efectiva para reducir las emisiones de gases de efecto invernadero y constituyen una fuente económica para producir energía o material combustible (Hansen et al., 2006). Con respecto al recambio de $\mathrm{N}$ orgánico a formas $\mathrm{NH}_{3} \mathrm{O} \mathrm{N}_{2} \mathrm{O}$ a diferencia del aeróbico en que el $\mathrm{N}$-orgánico se concentra en la parte sólida, en el anaeróbico se favorece su mineralización durante la digestión lo que incrementa su disponibilidad por la planta (Portejole et al., 2004).

Entre los tratamientos biológicos más utilizados a escala comercial para el manejo de residuos sólidos ganaderos se encuentra el composteo y la biometanización que se basan en la degradación bioquímica de la fracción orgánica biodegradable del residuo convirtiéndola en una sustancia con características estables e inofensivas desde el punto de vista higiénico y sanitario.

Compostaje.

En muchas circunstancias el composteo es preferido por ser un método fácilmente accesible, rápido y con disponibilidad de diversos tipos de sustratos orgánicos susceptibles a utilizar; el proceso ocurre naturalmente en un ambiente húmedo y cálido y puede ser acelerado con la aplicación de condiciones apropiadas tales como; 
Relación de nutrientes. La mayor parte de los microorganismos que participan en la descomposición requieren para su desarrollo una relación de carbono-nitrógeno $(\mathrm{C} / \mathrm{N})$ y fósforo (C/P) determinada. Para el compostaje, las proporciones de 30:1 y 100:1 en peso respectivamente, resultan adecuadas y pueden conseguirse mediante el mezclado de diferentes tipos de excretas o materiales orgánicos (Sommer y Dahl, 1999 ). Relaciones altas disminuyen la actividad biológica y menores causan pérdidas de nitrógeno en forma de amoniaco quedando el proceso incompleto (Sommer, 2001).

Humedad. Se recomienda un contenido entre 50 al 70\% para la degradación del material. Si se da un exceso, el proceso se vuelve anaeróbico generando gas metano y malos olores. De igual forma la falta de humedad disminuye la actividad de los microorganismos haciendo más lento el proceso (Walter, 1999).

Superficie de área. Conforme disminuye el tamaño de la partícula del material a compostear la velocidad de descomposición aumenta debido a una mayor área de contacto entre las partículas y los microorganismos (McKinley y Vestal, 1985). Cuando las compostas son demasiado pequeñas se resecan muy fácilmente y no pueden retener el calor necesario para una rápida degradación, mientras que demasiado grandes impiden la entrada de oxígeno hacia el centro de la composta y la degradación no se realiza de manera uniforme.

Temperatura. Se consideran temperaturas óptimas dentro de un intervalo de 35 a $55^{\circ} \mathrm{C}$ para conseguir la eliminación de patógenos, parásitos y semillas de malas hierbas. A temperaturas muy altas muchos microorganismos interesantes para el proceso mueren y otros no actúan al estar esporados (Larney et al., 2006).

Aireación y pH. La concentración de oxígeno dependerá del tipo de material, textura, humedad, frecuencia de volteo y de la presencia o ausencia de aireación forzada (Park et al., 2005). El pH Influye en el proceso debido a su acción sobre microorganismos, mientras que los hongos toleran un margen de $\mathrm{pH}$ entre 5 y 8, la capacidad de tolerancia para las bacterias es menor ( $\mathrm{pH}=6-7.5$ ) según Lay et al., 1997.

Población microbiana. Entre los diversos tipos de bacterias que intervienen en el proceso, las psicrofílicas son capaces de degradar la materia orgánica a bajas temperaturas y generar el suficiente calor para el crecimiento de las bacterias mesófilas que requieren un rango de temperatura medio entre $20^{\circ} \mathrm{C}$ a $35^{\circ} \mathrm{C}$ para desarrollarse; su actividad eleva la temperatura hasta los $45^{\circ} \mathrm{C}$ lo que propicia el crecimiento de las bacterias termofílicas que elevan la temperatura de la composta hasta $75^{\circ} \mathrm{C}$ y degradan la mayor parte del material; una vez que bajan su actividad, la composta reduce su temperatura (Diaz et al., 2002). Para que la composta alcance una calidad fertilizante deberá ser estable, con mínima concentración de materia orgánica fácilmente degradable, mínimo volumen, con máxima concentración de nutrientes (relación N:P:K adecuada) mínima concentración de compuestos tóxicos, nula concentración de patógenos, semillas de malas hierbas, larvas o huevos de insectos, olor agradable o en todo caso que no recuerde su origen. Se estima que en un mes luego de que alcance la 
temperatura del ambiente, la composta puede tener esas características (Petersen et al., 2003).

\section{Biometanización.}

La posibilidad de obtener energía mediante el tratamiento anaeróbico de residuos orgánicos ha adquirido gran interés en diversos países (Hohlfeld y Sasse, 1986) y algunos aspectos técnicos han sido desarrollados para adaptar esta tecnología a comunidades rurales (Nazir, 1991). En los biodigestores es posible transformar más de $90 \%$ de la energía disponible para oxidación directa a metano y utilizar solo $10 \%$ para el crecimiento bacteriano; además del biogas (mezcla de dióxido de carbono, metano y elementos traza) se obtiene un efluente líquido de alta calidad fertilizante (Castro et al., 2001). La mayoría de los sistemas de digestión anaeróbica de desechos de ganado operan dentro de rangos mesofílico $\left(35 \mathrm{a} 37^{\circ} \mathrm{C}\right.$ ) aunque en los últimos años existe una tendencia a pasar a rangos termófilios con temperaturas mayores de $40^{\circ} \mathrm{C}$ para aumentar la producción de biogás y la destrucción de organismos patógenos (Hansen et al., 2006). Esto requiere más gasto calórico por lo que en países poco templados podrían resultar termodinámicamente menos estables (Hopson, 1990).

\section{Factores que intervienen en el proceso de biometanización}

La digestión anaerobia requiere del estricto control de diversos factores ambientales (temperatura, $\mathrm{pH}$ del medio, presencia de sustancias tóxicas) y operacionales (disponibilidad de nutrientes, tiempo de retención (THR) y nivel de carga) que condicionan el desarrollo de las diferentes poblaciones microbianas que actúan en el proceso (Sosa et al., 2003). Las etapas bioquímicas y las poblaciones microbianas implicadas en el proceso anaeróbico se esquematizan en la Figura 1.

Figura 1. Fases de la fermentación anaeróbica y bacterias que intervienen. Los números indican la población bacteriana responsable del proceso: 1: bacterias fermentativas; 2: bacterias acetogénicas que producen hidrógeno; 3: bacterias homoacetogénicas; 4: bacterias metanogénicas hidrogenotróficas; 5: bacterias metanogénicas acetoclásticas. (Pavlostathis y Giraldo-Gómez,1991).

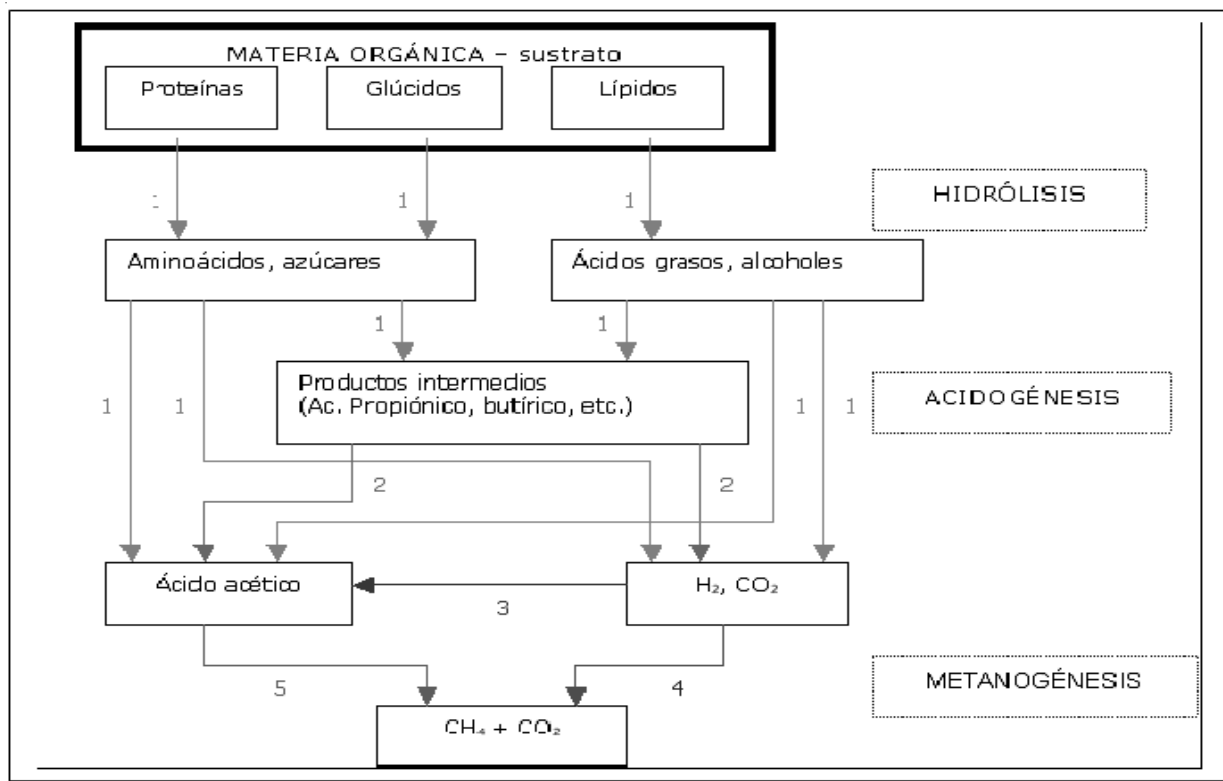


Los grupos de bacterias trabajan de manera simbiótica y secuencial generando los sustratos y condiciones del medio para el crecimiento de las subsecuentes poblaciones. De esta forma las bacterias hidrolíticas descomponen las cadenas largas de compuestos orgánicos en intermediarios de cadena más corta que son consumidos por organismos fermentativos durante la etapa acido génica; estos a su vez crean las condiciones anaeróbicas y sustratos orgánicos (ácidos grasos volátiles, ácido acético, fórmico, $\mathrm{H}_{2}$ ) que son utilizados directamente por las metanogénicas (Stams, 1994) que los transforman a metano.

Dado que las tasas de crecimiento de las bacterias metanogénicas son cinco veces menores que las de la fase anterior, estas son responsables directas del desarrollo del proceso, de modo que condicionan el tiempo de retención (THR) o permanencia del material en el reactor y la temperatura de trabajo (Campos, 2001a). Para asegurar la formación anaerobia de metano deberán considerarse los siguientes parámetros:

$\mathrm{pH}$ y alcalinidad. Los procesos biológicos y químicos implicados se desarrollan a rangos de $\mathrm{pH}$ cercanos a la neutralidad. Valores de pH inferiores a 6.0 ó superiores a 8.0 dificultan el crecimiento microbiano y el equilibrio químico de las reacciones dando lugar a la formación o acumulación de sustancias que causan efectos inhibitorios, como los ácidos grasos volátiles (AGVs) que se acumulan en la fase acetogénica por la baja velocidad de consumo de las metanogénicas (Hwu et al.,1997), provocando un descenso del pH e inhibición del crecimiento bacterial. Igualmente valores de $\mathrm{pH}$ alcalinos favorecen el desplazamiento del equilibrio amonioamoniaco hacia la formación de amoniaco libre con efectos tóxicos a las bacterias metanogénicas (Lay et al., 1997).

Los métodos que se aplican para corregir las variaciones de $\mathrm{pH}$ durante el proceso, regulan los periodos de carga de alimentación en el digestor y deja que las bacterias metanogénicas asimilen los AGVs hasta que se incremente el $\mathrm{pH}$ a un nivel aceptable o se adicionan sustancias bufferantes para aumentar el $\mathrm{pH}$ como el agua con cal (Campos, 2001a). Aunque el monitoreo del $\mathrm{pH}$ refleja un estado del sistema, las variaciones pueden resultar demasiado lentas y una vez detectadas su recuperación podría ser inevitable, por lo que es conveniente monitorear otras variables tales como la producción de biogás y contenido de metano, contenido de AGVs, presión parcial de hidrógeno o indicadores de la población bacterial (Burak et al., 2005). Para residuos de porcinos y aves con alcalinidades altas las caídas de $\mathrm{pH}$ son poco importantes aun cuando se produzcan acumulaciones de AGVs (Campos, 2001b).

Temperatura. Aunque el crecimiento bacteriano y por tanto la producción de biogás en ausencia de inhibidores se favorece con la temperatura las poblaciones anaeróbicas son especialmente sensibles a los cambios de esta variable, ya que sus niveles óptimos de crecimiento y metabolismo se desarrollan a rangos muy definidos para cada grupo en particular (Hansen et al., 2006). Las bacterias metanogénicas resultan ser especialmente susceptibles por sus velocidades de crecimiento más lentas que las acidogénicas (Stams, 1994). Altas temperaturas causan destrucción en las enzimas celulares e influyen en importantes equilibrios químicos del proceso como el 
Cristina Elizabeth Vélez-Sánchez-Verín, Carmelo Pinedo-Álvarez, Oscar A. Viramontes-Olivas, Carlos Ortega Ochoa, Alicia MelgozA-CASTILLO: Bio-tecnologías ambientales para el tratamiento de residuos ganaderos

amonio-amoníaco libre o ácidos grasos volátiles ionizados-no ionizados, que favorecen las formas no ionizadas que resultan tóxicas para los microorganismos (Campos, 2001b).

Nutrientes. Aunque los tratamientos anaeróbicos se caracterizan por sus bajos requerimientos de nutrientes; una proporción adecuada de nitrógeno y fósforo es necesaria para el crecimiento de la población bacteriana. Algunos autores reportan la relación de estos nutrientes en función de la concentración de carbono considerando que la proporción $\mathrm{C} / \mathrm{N}$ debe oscilar entre 15-30/1 y de C/P de 75113/1; valores muy inferiores disminuyen la velocidad de reacción y superiores crean problemas de inhibición del proceso biológico (Speece, 1987). Otros nutrientes que se requieren en cantidades mínimas son el sulfuro, cobalto, níquel, molibdeno, selenio, riboflavina y vitamina B12 (Campos 2001a). En general los residuos ganaderos suministran una suficiente concentración de todos los nutrientes siendo más común la presencia de problemas por exceso que por defecto (Moss et al., 2000).

Toxicidad. La presencia de ciertos compuestos de metales, antibióticos, sales y bactericidas a bajas concentraciones alteran los procesos biológicos y afectan la digestión aun los nutrientes esenciales a altas concentraciones causan efectos tóxicos, siendo las bacterias metanogénicas las más sensibles (Stams, 1994). En alimentos para ganado con elevado contenido de proteína, un desbalance debido a altos contenidos de nitrógeno y bajas disponibilidades energéticas causa toxicidad por generación de amonio. Las concentraciones inhibitorias son variables y dependen de la capacidad de aclimatación de las bacterias las cuales están relacionadas con el $\mathrm{pH}$ y la temperatura (Hashimoto, 1986).
Parámetros de construcción. Para lograr una máxima producción de biogás, deben considerarse criterios relacionados con el nivel de carga y tiempo de retención (THR) para el diseño y tamaño del digestor. El nivel de carga constituye la cantidad de materia seca total (MS) o parte de la materia orgánica (MO) que es alimentada diariamente por metro cúbico del volumen de digestor. La MO esta compuesta por la parte de la MS o sólidos volátiles (SV) que teóricamente se fermentan para ser convertidos a metano y el TRH es el tiempo que las bacterias disponen para completar el proceso en el digestor.

EI THR de los desechos en un digestor está determinado por el diseño del digestor, las fluctuaciones de la temperatura y composición de los desechos (Ahring et al., 1992). Para los residuos ganaderos suele variar de $10 \mathrm{a}$ $30 \mathrm{~d}$. y el contenido de SV no debe exceder al $10 \%$ en la mayoría de los casos, por eso, los residuales de granjas deben de diluirse antes de ser tratados. El mezclado y tamaño de partículas influyen en la disponibilidad de las superficies a la acción bacteriana y previene la disminución de ésta por agotamiento puntual de los nutrientes 0 acumulación de metabolitos (Dugba y Zhang, 1999).

La eficiencia del digestor es estimada por la cantidad de MO degradada por unidad de volumen del digestor. Al aumentar el THR la fracción de materia orgánica degradada aumenta, sin embargo una vez superado el óptimo la producción volumétrica de metano (producción por unidad de reactor disminuye. Para materiales fácilmente degradables, se requieren THR más 
cortos y tamaños de digestores más pequeños. Por tanto, para cada tipo de residuo y volumen de digestor se necesita determinar el tiempo de retención que optimiza el proceso (Castro et al., 2001).

Estrategias de tratamiento de desechos líquidos

El tratamiento de aguas residuales provenientes de establos también deberán ser consideradas para un manejo integral de desechos pecuarios. A pesar de que la separación de las fracción líquida del estiércol contribuye de manera significativa a la reducción de su potencial contaminante, el líquido que se queda después de la separación aun representa una amenaza al medio ambiente (Marino y Boland, 1999 ) en la mayoría de los casos su aplicación cuidadosa al suelo permite la eliminación segura, sin embargo en condiciones especificas de una granja puede ser poco indicado. Entre las estrategias disponibles para el tratamiento de los desechos líquidos ganaderos se describen:

Utilización de lagunas. El estiércol líquido antes o después de ser separado de la fracción sólida, puede ser tratado en lagunas aeróbicas o anaeróbicas. En ambos casos el material orgánico es total o parcialmente mineralizado y parte de los nutrientes se descargan a través de la fase liquida a aguas superficiales o se usan para riego (Craggs et al.,2003). Al igual que en el proceso de composteo las bacterias oxidan los compuestos contaminantes como los AGVs presentes en el lodo haciéndolo menos ofensivo con menos olores y emisiones de metano durante el almacenamiento y en el momento de la aplicación al suelo; por medio de la nitrificación y desnitrificación subsiguiente, existe una reducción en el contenido de nitrógeno amoniacal, de la demanda biológica de oxigeno (DBO) del lodo y la inactivación de muchos patógenos, aunque no siempre se logra una desinfección completa, los productos finales son $\mathrm{CO}_{2}, \mathrm{H}_{2} \mathrm{O}$ y $\mathrm{N}_{2}$ (Grommen y Verstraete, 2002). En lagunas anaeróbicas la degradación del material orgánico se hace de manera parcial; mayores reducciones de DBO suelen alcanzarse tras la separación de la fracción sólida del estiércol antes de la digestión, aunque se reduce el rendimiento de biogas (Moss et al., 2000). De las tecnologías emergentes que contribuyen a mejorar las características fermentativas de los compuestos recalcitrantes son la ozonización, molienda del material (Weemaes et al., 2000) y la gasificación subcrítica (Misch et al., 2000). Con respecto a los procesos de eliminación de nitrógeno, biotecnologías como procesos de oxidación de amonio (Fdz-Polanco et al., 2001) y la nitrificación y desnitrificación en condiciones bajas de oxigeno en los que nitrificantes convencionales generan la producción de $\mathrm{N}_{2(\mathrm{~g})}$ (Grommen y Verstraete, 2002) han ganado terreno en el campo de la fisiología microbial.

Uso de filtros biológicos o humedales. Constituyen una alternativa de bajo costo para el tratamiento de aguas residuales de pequeños núcleos urbanos; se fundamentan en el uso de plantas fijadas con grava, de modo que al escurrir la corriente de agua por sus raíces, las bacterias que se acumulan degradan el material orgánico (García et al., 1997). Para cualquier sistema incluyendo desechos líquidos ganaderos, pueden idearse como tratamiento terciario después de un tratamiento biológico (lagunas o bio-digestores) obteniéndose 
mejores niveles de depuración.

Entre otros tratamientos físicos, la eliminación de amoniaco por "stripping" y absorción genera como producto una solución concentrada de sal de amonio que requiere un tratamiento posterior para su utilización; mientras que por la electro- remediación se hace pasar una corriente eléctrica á través de la fase líquida del estiércol que provoca la precipitación de los iones metálicos en el electrodo y permite disminuir la concentración de metales pesados (Dash y Starmans, 2006). En cambio en la nitrificación como tratamiento biológico, el amonio sufre una conversión a nitrito que en combinación de un proceso de desnitrificación, se convierte en nitrógeno gaseoso $\left(\mathrm{N}_{2}\right)$ (Kuai y Verstraete, 1998).

Diversas estrategias de manejo y tecnologías ambientales son requeridas para controlar el exceso de nutrientes y otros riesgos en ecosistemas; sin embargo el desarrollo se ve limitado por políticas económicas y regulaciones de manejo de desechos que presentan condiciones limitantes para determinar si una tecnología dada es la más adecuada para el ganadero. En el Cuadro 1 se resumen las características básicas de algunos procesos aplicados a los desechos ganaderos. Debido a la amplia variedad de procesos de tratamiento existentes, es importante limitar la elección de las técnicas probadas de acuerdo a las alternativas y necesidades existentes en las unidades de producción y considerar la calidad y variabilidad de las excretas a tratar, así como los costos asociados al proceso. En mucho de los casos, la combinación de dos o más tratamientos resulta necesario para alcanzar un objetivo en particular (Verstraete, 2002). La Figura 2 representa un esquema propuesto de los procesos unitarios que pueden aplicarse para el tratamiento de los desechos sólidos y líquidos provenientes de los sistemas ganaderos intensivos.

\section{Conclusiones}

La producción ganadera no es un negocio fácil y es comprensible que los productores no vean con buenos ojos el tener más restricciones. No obstante, se beneficiarían al tener un ambiente más limpio, de tal manera que es muy importante tomar acciones inteligentes fundamentadas en principios científicos para adoptar técnicas para manejar y tratar los estiércoles y aguas residuales generados en las unidades de producción. La evaluación de los riegos de contaminación causados por excedentes de nutrientes es el primer paso en dicho proceso, y el segundo es tomar en cuenta las múltiples tecnologías de tratamiento disponibles para reducir el riesgo. Si la elección de las técnicas o estrategias no está completamente clara, debe considerarse que a pesar de la gran diversidad de los sistemas de producción, los principales problemas ambientales que afectan el agua, aire y suelo son compartidos por ganaderos en todas partes del mundo, y ellos están de acuerdo en la necesidad de seleccionar las mejor manera de ayudar a los demás y hacer las elecciones correctas. 
Cuadro 1. Operaciones aplicadas al tratamiento de residuos ganaderos.

(T: residuo íntegro; S: fracción sólida; L: fracción líquida).

\begin{tabular}{|c|c|c|}
\hline Proceso & $\begin{array}{l}\text { Fracción } \\
\text { que se } \\
\text { aplica }\end{array}$ & Objetivo \\
\hline $\begin{array}{l}\text { Almacenamiento } \\
\text { (estercoleros, balsas de } \\
\text { homogenización) }\end{array}$ & T: S: L & $\begin{array}{l}\text { Regularla producción continua al consumo estacional } \\
\text { de cultiwos. } \\
\text { Regular entradas discontinuas a plantas de tratamiento. } \\
\text { Reducir patógenos. }\end{array}$ \\
\hline Separación de fases & $\mathrm{T}$ & $\begin{array}{l}\text { Separar para propiciar líneas específicas de } \\
\text { tratamiento, transporte ó aplicación de la fracción sólida } \\
\text { ó líquida resultante. }\end{array}$ \\
\hline $\begin{array}{l}\text { Aplicación de encimas y } \\
\text { bacterias a depósitos de } \\
\text { almacenamiento }\end{array}$ & $\mathrm{T}$ & $\begin{array}{l}\text { Aumentar la concentración de sólidos. Transformar N } \\
\text { amoniacal a orgânico. }\end{array}$ \\
\hline Nitrificación & L & Transformar $\mathrm{N}$ amoniacal a nítrico. \\
\hline Desnitrificación & L & $\begin{array}{l}\text { Transformar } \mathrm{N} \text { nítrico a } \mathrm{N}_{2} \text {. Eliminar matéria orgânica } \\
\text { facilmente degradable. }\end{array}$ \\
\hline $\begin{array}{l}\text { Descomposición aeróbica } \\
\text { heterótrofa }\end{array}$ & L. T & Eliminar matéria orgânica \\
\hline Digestión anaeróbia & T. S. L & $\begin{array}{l}\text { Producir } \mathrm{CH}_{4} \text { (energia), Eliminar materia orgánica. } \\
\text { Higienizar. }\end{array}$ \\
\hline $\begin{array}{l}\text { Reducción biológica de } \\
\text { fóstoro }\end{array}$ & L & $\begin{array}{l}\text { Transterir P soluble a fase biológica sedimentable. } \\
\text { Eliminar materia orgánica fácilmente degradable. }\end{array}$ \\
\hline $\begin{array}{l}\text { Precipitación } \\
\text { química }\end{array}$ & L & $\begin{array}{l}\text { Transferir algunos componentes a fase } \\
\text { sedimentable. Separar } P \text {. }\end{array}$ \\
\hline Secadolpeletización & $\mathrm{s}$ & Separar agua. Reducir volumen. \\
\hline $\begin{array}{l}\text { Evaporacióni } \\
\text { concentración }\end{array}$ & L & Separar agua. Reducir volumen. \\
\hline $\begin{array}{l}\text { Stripping } \\
\text { absorción }\end{array}$ & L & Recuperar N amoniacal. \\
\hline Higieniza ción térmica & $\mathrm{T}$ & Eliminarínactivar patógenos \\
\hline $\begin{array}{l}\text { Dosificación de } \\
\text { aditivos }\end{array}$ & T.S.L & $\begin{array}{l}\text { Modificar composición para adecuarla a cultivos ó } \\
\text { posibilitar procesos. }\end{array}$ \\
\hline Dzonización & L & Oxidación compuestos orgánicos recalcitrantes. \\
\hline $\begin{array}{l}\text { Filtración en } \\
\text { membranalosmosis } \\
\text { inversa }\end{array}$ & $\mathrm{L}$ & Separar sales. Reducir conductividad. \\
\hline
\end{tabular}


Figura 2. Estrategia de tecnologías propuestas para el tratamiento de desechos (heces y orines) generados en unidades ganaderas intensivas.

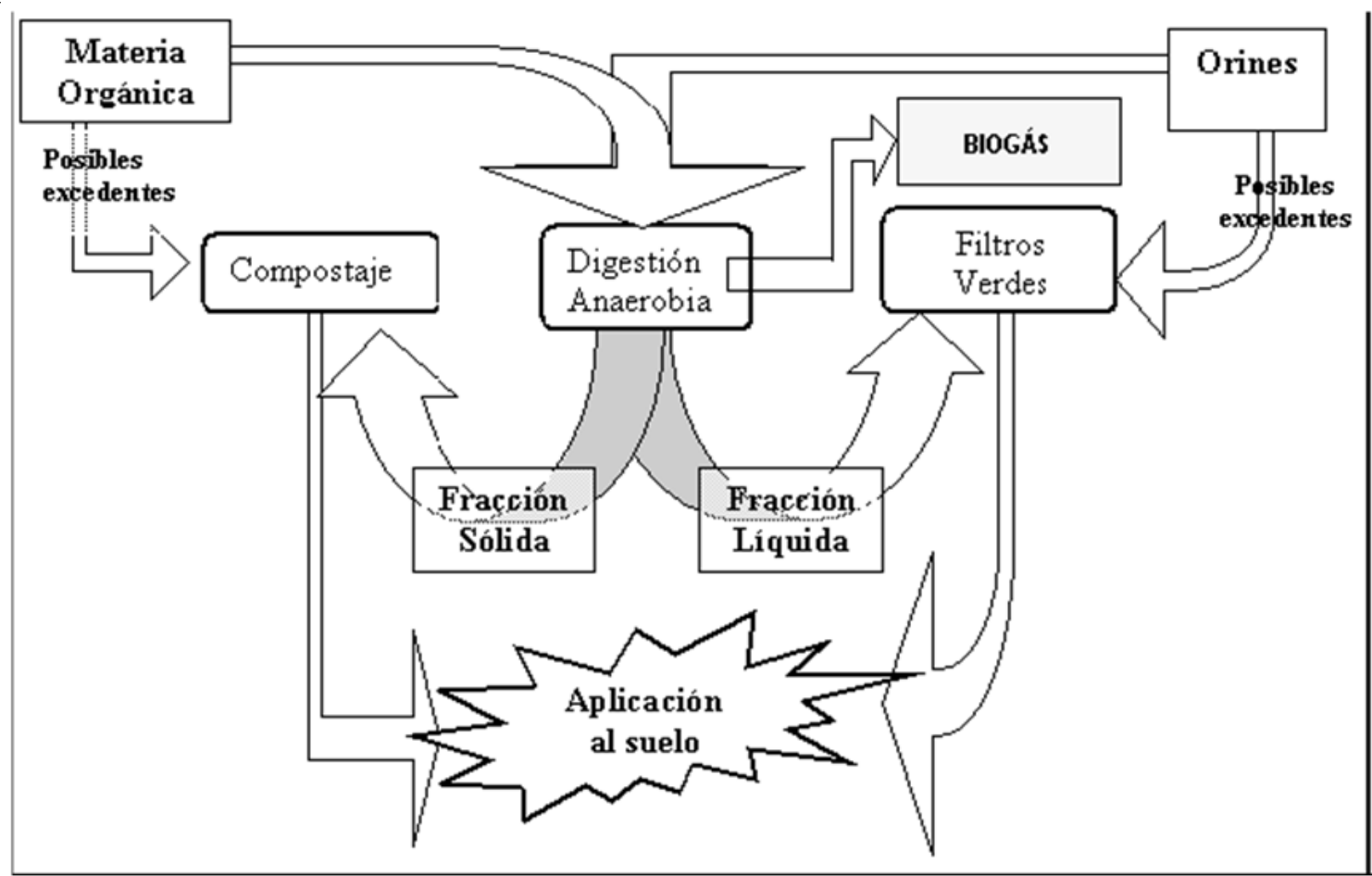

\section{Literatura citada.}

AHRING, B.K., I. Angelidaki and K. Johansen. 1992. Anaerobic treatment of anure together with industrial waste. Wat. Sci. Tech., 25: 311-318.

Amon, B., R. Kryvoruchko, T. Amon, and S. Zechmeister-Boltenstern. 2006. Methane, nitrous oxide and ammonia emissions during storage and after applications of dairy cattle slurry and influence os slurry treatment. Agric. Ecosyst. Environ. 112: 152-162

Вонм, R. 2004. Hygienic safety in organic waste management. In: Lens, P., Hamelers, B., Hoitink, H., Bidlingmaier, W. (Eds), Resourse recovery and reuse in organic soild waste management. IWA publishing,London. 459-482 p.

BuRAK, D., Y. Orhan and T. Turgut . 2005. Anaerobic treatment of dairy wastewaters: a review. 40(8): 2583-2595.

BURTON, C.H. and C. Turner. 2003. Manure management: Treatment strategies for sustainable agriculture. 2nd ed. Silsoe Research Institute, Wrest Park, Silsoe, Bedford, UK. 490 p.

CAMPOS, P. 2001a. Optimización de la digestión anaeróbica de purines de cerdo mediante la codigestión con residuos orgánicos de la industria agroalimentaria. Tesis Doctoral. Universidad de Lleida, España.

CAmpos, E. 2001b. Aprovechamiento energético de lodos residuales y purines. Producción de Biogás [en línea]. Journals Técnicos sobre energía. Barcelona Noviembre 2001. http//:www.udl.es/ usuaris/lea/cast/web9.htm [Consulta: $10 \mathrm{Abr} 2005]$.

CAstro G., M. Enríquez and C. Durán-de-Bazula. 2001. Design, Construction, and Starting-up o fan anaerobic reactor for the stabilization, handling, and disposal of excess biological sludge generated in a wastewater treatment plant. Anaeobe Biotechnology.

142
CRAGGS, R.J., C.C..Tanner, J.P.. Sukias and R. J. Davies-Colley. 2003. Dairy farm wastewater treatment by an advance pond system. Water Science and Technology. 48(2): 291298.

DASH, J. and D.A. Starmans. 2006. Electroremediation of heavy metals from liquid manure In: Petersen, S.O.(Ed), Technology for Recycling of manure and organic residues in a Whole Farms Prespective. Vol II. Danish Insititute of Agricultural Sciences. $165-168 \mathrm{p}$.

DIAZ, L.F., Savage, G.M. and C.G. Golueke. 2002. Composting of Municipal Solid Wastes. In G. Tchobanoglous \& F. Kreith (Eds.) Handbook of Solid Waste Management. New York: McGraw. 30p.

DugBA, P. y Zhag, R. (1999). Treatment of dairy wastewater with two-stage anaerobic sequencing batch reactor systemthermophilic versus mesophilic operations. Bioresource Technology 68: 225-223.

Fdz-Polanco, F., M. Fdz-Polanco, N. Fernandez, M.A. Uruena, P.A. Garcia and S. Villaverde. 2001. New process for simultaneous renoval of nitrogen and sulphur under anaerobic conditions. Waste Research 35 : 1111-1114

Flotats, X., A. Bonmatí, E. Campos y M.R. Teira. 2000. El proceso de secado de purines en el marco de gestión integral de residuos ganaderos. Residuos. 53: 40-46.

GARCIA, J., A. Ruiz y X. Junqueras. 1997, Depuración de aguas residuales mediante humedales construidos. Tecnología del agua. 165: 58-65.

Grommen, R. and W. Verstraete. 2002. Enviromental biotechnology:The ongoing quest. J. Biotechnology 98: 113-123.

Hansen,T.L., G.S. Svend, G. Soren and T.H. Christesen. 2006. 
Methane Producction during storage of anaerobically digested municipal organic waste. J. of Enviromental Quality $35: 830$ 836.

HASHIмото, A.G., 1986. Ammonia Inhibition of methanogenesis from cattle wastes. Agricultural Wastes. 17: 241-261p.

Hobson, P.N., 1990. The treatment of agricultural wastes", En Anaerobic Digestion: a waste treatment technology. Editado por Wheatley, A critical reports on applied chemistry. 31: 93138 p. Elsevier applied science LTD.

HohlFELD, J and L Sasse. 1986. Production and utilization of biogas in rural areas of industrialized and developing countries. Eschborn. Federal Republic of Germany p 51-96

Hwu, C.S., B. Donlon and G. Lettinga, 1997. Acute toxicity of oleate to acetate-utilizing methanogens in mesophilic and thermophilic anaerobic sludges. Enzyme and Microbial Technology. 21: 297-301.

KUAl, L.P. and W. Verstraete. 1998. Ammonium removal by the oxygen-limited autotrophic nitrification-desnitrification system. Applied and Environmental Microbiology. 64: 4500-4506-

LARNEY, F.J., K.E. Buckley, X.Y. Hao and W.P. McCaughey. 2006. Fresh stockpiled and composted beef cattle feedlot manure nutrient levels and mass balance estimates in Alberta and Manitoba . J. Enviroment Qual. 35: 1844-1854.

LAY, J.J., Y.Y. Li and T. Naike. 1997. Influences of $\mathrm{pH}$ and moisture content on the methane production in high-solids sludge digestion. Water Research,31 (10):1518-1524.

MARINo, M. and J. Boland. 1999. An Integrated approach to wastewater treatment. Water Environment Research 46(5) :1-46

MCKINLEY, V.L. and Vestal, J.R. 1985. Physical and Chemical Correlates of Microbial Activity and Biomass in Composting Municipal Sewage Sludge. Appl. Environ Microbiol. 50(6): 1395-1403

MiLleR, D.N and E.D. Berry. 2005. Cattle feedlot soil moisture and manure content:1. Impacts on greenhouse gases, odor compounds, nitrogen loses and dust. J. Enviromental Qual. 34: 644-655.

$\mathrm{Misch}, \mathrm{B}$., A. Firus and G. Brunner. 2000. An anlternative method of oxidizing aquosous waste in supercritical water: oxygen supply by means of electrolysis. J. of Subcriical Fluids. 17: 227-237.

Moss, A., J.P. Jouany and J. Newblod. 2000. Methane Production by ruminants: its contribution to global warming. Ann. Zootech. 49: 231-253.

NAZIR, M. 1991. Biogas plants construction technology for rural areas. En: Bioresource Technology, Barkin, 35: 283-289.

Nicholson, F.A. and B.J. Chambers. 2006. Quntifying heavy metal inpunts to agricultural soils in England and Wales. In: Petersen, S.O. (Ed), Technology for Recycling of Manure and Organic Residues Agricultural Sciences, p. 41-44.

OcYASA MEDIOAMBIENTAL ,S.L. 2002. Proyecto $i+d$ industria ganadera de Cantabria. Grupo de ingeniería ambiental. OCYASA Medioambiental, s.f. Tomo II, fase IV "Medios receptores".

OlymAR, M. y E. Reyes. 2003. Tecnologías limpias aplicadas a la agricultura. INCI 28 (5): 252-259.

PARK, K.J., Zhu, J. and Z. Zhang, 2005. Influence of aeration rate and liquid temperature on ammonia emission rate and manure degradation in aerobic treatment. Trans. ASAE48: 321-330

P Pavlostathis, S.G. and E. Giraldo-Gómez. 1991. Kinetics of anaerobic treatment: a critical review. Critical reviews in environmental control. 21 (5,6),:411-490.

Petersen, S.O., K. Henriksen , G.K. Mortensen, P.H. Krogh, K.K. Brandt, J.Sorensen, T. Madsen, and C. Gron. 2003. Recycling of sewage sludge and household compost to arable land: fate and effects of organic contaminants, and impact on soil fertility. Soil Tillage Res. 72:139-152.

Petersen, S.0., S.G. Sommer., F, Béline., C. Burton., J, Dach., J.Y., Dourmad., A. Leip., T. Misselbrook., F. Nicholson., H.D. Poulsen., G. Provolo., Sorensen,P., A Vinneras., A. Weiske., M.P. Bernal., R. Bohm., C. Juhász and R. Mihelic. 2007. Recycling of livestock manure in whole-farm perspective. Livestock Science. 112: 180-191.

PORTEJOLE, S., J.K. Dourmard, J- Martínez and Y. Lebreton. 2004. Effects of lowering crude protein on nitrogen excretion, manure composition and ammonia emission from fattening pigs. Livest. Prod.Sci. 91: 45-55.

RIETHMULLeR, P. 2003. The social impact of livestock: Adeveloping country perspective, Animal Journal Sci. 74:245-253

SIMS, J. T. L., B.T Bergstrom and O. Oenema, 2005. Nutrient management for intensive animal agricultura: policies and practices for sustainabilitiy. Soil Use Mange 21: 141-151.

Sommer, S.G. and P. Dahl. 1999. Nutrient and carbon balance during the composting of deep litter. J. Agric. Eng. Res. 74: 145-153.

Sommer, S.G. 2001. Effect of composting on nutrient loss and nitrogen availability of cattle deep litter. Eur. J.Agron.14: 123-133.

SoRENSEN, P. and I.K. Thomsen. 2005. Separation of pig slurry and plant utilization and loss nitrogen-15-labeled slurry nitrogen. Soil Sci. Soc. Am.J. 69: 1644-1651

Sosa R., J. Del Río y R. Chao. 2003. Aspectos Bioquímicos y tecnológicos del tratamiento de residuales agrícolas con producción de biogás. [en línea] Instituto de Investigaciones porcinas, Punta Brava. La Habana, Cuba. <http:// www.sian.info.ve/porcinos/publicaciones/producerdos/ articulo7.htm>. [Consulta: 13 Jun 2005].

SOYEZ, K., and S. Plickert. 2002. Mechanical-Biological PreTreatment of Waste -

State of the Art and Potentials of Biotechnology. Acta Biotechnologica 22 (Issue 3-4): $271-284$.

SpeEce, R. E., 1987.Nutrient Requeriments. En: Anaerobic digestion of biomass. Chynoweth y Isaacson (eds.). Elsevier applied science. p 67- 72

Stams, A.J.M. 1994. Metabolic interactions between anaerobic bacteria in

methanogenic environments. Antonie van Leeuwenhoek. 66: 271-294 p.

TAmmingA, S. 2003. Pollution due to nutrient losses and its control in European animal production. Livest. Prod. Sci.84: 101111.

Vélez, C, G. Cuevas, C. Pinedo, L. Losoya y E. Turcoott. 2008. Diseño de un plan de gestión para los residuos sólidos generados por el sector ganadero en el municipio de Chihuahua, México), Ingeniería Sanitaria y ambiental. www.aidis.org.mx (in press).

Verstraete, W. 2002. Environmental biotechnology for sustainability. J. of Biotechnology 94: 93-100.

WALKER, J. K. 1999. Suitability of composted dairy manure for plant production in New Mexico Master's Thesis. New México State University. Las Cruces Nm.

Weemaes, M., H. Grootaerd, F. Simoens, A. Huysmans and W. Verstraete. 2000. Ozonation of sewage sludge prior to anaerobic digestion. Water Science and Technology 42: 175178. (6) 


\section{Resúmenes curriculares de autor y coautores}

Cristina Elizabeth Vélez Sánchez Verín. En 1983 obtuvo el titulo de Ingeniero Químico Bromatólogo, por la Facultad de Ciencias Químicas de la Universidad Autónoma de Chihuahua (UACH). Realizó estudios de doctorado, otorgándosele en 1990 el grado de Doctor en Ciencias Biológicas, por la Universidad Autónoma de Madrid, España. Durante el 2001 obtuvo su post doctorado con especialidad en Ciencias Ambientales, en el Centro de Investigaciones de Materiales Avanzados (CIMAV); durante ese periodo trabajó sobre el aprovechamiento de residuos aplicando procesos químicos y biológicos. La Dra. Vélez ha dirigido tesis de licenciatura y posgrado y publicado 20 artículos en revistas arbitradas internacionales; además, su producción académica incluye 18 resúmenes y 30 artículos en extenso publicados en memorias de congresos científicos, sobre toxicología y farmacología de especies aviares. La Dra. Vélez es miembro del Sistema Nacional de Investigadores (S.N.I.) y profesora de tiempo completo de la Facultad de Zootecnia $(\mathrm{UACH})$, y sus proyectos de investigación están enfocados al monitoreo y evaluación de recursos naturales, entre los que destaca el desarrollo del proyecto "Diseños de planes de gestión para los residuos pecuarios y tecnologías de aprovechamiento para la producción de combustibles alternos (biogas) y fertilizantes sólidos".

Carmelo Pinedo Álvarez. Terminó su licenciatura en 1978, año en que le fue otorgado el título de Ingeniero Zootecnista, por la Facultad de Zootecnia de la Universidad Autónoma de Chihuahua (UACH). Realizó estudios de posgrado en la Facultad de Contaduría y Administración (UACH), obteniendo en 1986 el grado de Maestro en Manejo de Recursos Humanos. En el año de 1998, finalizó su programa doctoral en la Facultad de Zootecnia (UACH), otorgándosele el grado de Doctor in Philosophy con especialidad en Manejo de Recursos Naturales. Desde 1999 labora en la UACH y posee la categoría de Académico Titular C. Es autor y coautor de numerosos artículos publicados en revistas indexadas nacionales e internacionales. Ha participado como ponente en numerosos congresos científicos y como evaluador de proyectos de investigación y programas educativos. Como profesor, ha dirigido numerosas tesis de licenciatura, maestría y doctorado. Durante su vida profesional ha sido distinguido con diversos reconocimientos por su productiva labor científica; siendo las principales áreas de especialización el monitoreo de recursos naturales y sistema de información geográfica.

Oscar A. ViRamontes Olivas. Cursó su licenciatura (1981-1985) en la Facultad de Zootecnia de la Universidad Autónoma de Chihuahua (UACH). En la misma facultad realizó estudios de posgrado (1991-1993), cursando la Maestría en Ciencias en Producción Animal, con especialidad en Reproducción y Genética Animal, otorgándosele una mención en su área. Durante el periodo 2005-2008, realizó estudios de doctorado en el Instituto de Ciencias Agrícolas de la Universidad Autónoma de baja California (UABC), otorgándosele en el año 2008 el grado de Doctor en Ciencias, siendo el tema de su disertación: "Evaluación de las propiedades hidráulicas del suelo superficial aplicando un modelo de escurrimiento en la Cuenca del Río Conchos". En el periodo 19811985 trabajó para la Facultad de Medicina de la UACH, ocupando el cargo de Jefe del Departamento de Animales de Investigación; a partir de 1985 se incorpora a la Facultad de Zootecnia, colaborando en una variedad de tareas académicas y científicas, pudiendo señalarse entre algunas áreas las de: Extensión y Difusión, Planeación, Reproducción y Genética, Recursos Naturales y Ecología. Su vida profesional abarca una larga experiencia editorial en diferentes periódicos y revistas científicas, escribiendo sobre diversos temas; además, es autor del libro "La Rabia". Ha colaborado con el Cuerpo Académico "Agua y Suelo" del Instituto de Ciencias Agrícolas de la UABC; mientras que en la Facultad de Zootecnia de la UACH, colabora activamente en el Cuerpo Académico "Ecología y Recursos Naturales".

Carlos Ortega Ochoa. El Dr. Ochoa cursó su licenciatura en la Facultad de Zootecnia de la Universidad Autónoma de Chihuahua $(\mathrm{UACH})$, obteniendo en 1986 el título de Ingeniero Zootecnista. Realizó estudios de posgrado en lowa State University, otorgándosele en el año de 1993, el grado de Maestro en Ciencias con un mayor en Agronegocios. Sus estudios de doctorado los realizó en Texas Tech University, institución que le otorgó en mayo de 2006 el Doctorado en Ciencias, con un mayor en Manejo de Pastizales y un menor en Economía Agrícola. Es Maestro de Tiempo Completo, posee el Perfil PROMEP y se encuentra adscrito a la Facultad de Zootecnia y Ecología (UACH). Es Miembro del Cuerpo Académico de Recursos Naturales y Ecología. Ha publicado artículos científicos en diversas revistas arbitradas y de divulgación. Actualmente ocupa el cargo de Presidente del Colegio Nacional de Ingenieros Zootecnistas, A. C. (2007-2009). Desde el año 2006 es Miembro de del Consejo Consultivo Pecuario de la Fundación Produce Chihuahua, A. C. También es Miembro de la Sociedad Internacional de Manejo de Pastizales, ocupando el cargo de Presidente de la Sección México desde el año 2008.

Alicia Melgoza Castillo. En 1977 obtuvo el título de Bióloga por la Facultad de Ciencias Biológicas, Universidad Autónoma de Nuevo León. Realizó estudios de maestría en la Universidad Estatal de Arizona, obteniendo en 1985 el grado de Maestría en Ciencias, especialidad Manejo de Pastizales. En 1995 obtuvo su Doctorado en Ciencias, en la especialidad de Ecología de Pastizales, grado que le fue otorgado por New Mexico State University. Ha trabajado en el Instituto Nacional de Investigaciones Forestales Agrícolas y Pecuarias y como asistente de investigación en el Departamento de Agricultura de los Estados Unidos de Norteamérica. Actualmente ocupa la plaza de Maestro de Tiempo Completo en la Facultad de Zootecnia y Ecología, Universidad Autónoma de Chihuahua. Ha publicado escritos científicos en revistas arbitradas e indexadas, contándose entre ellos notas de investigación, artículos científicos, folletos técnicos, capítulos de libros y libros. Es evaluadora de proyectos del CONACYT; tambiés es árbitro de revistas nacionales e internacionales, señalándose entre ellas: Técnica Pecuaria en México, Journal of Arid Environment y African Journal of Botany. Ha recibido diversos reconocimientos por parte de organizaciones nacionales e internacionales, siendo uno de ellos el reconocimiento como Miembro del Sistema Nacional de Investigadores (S.N.I.). 